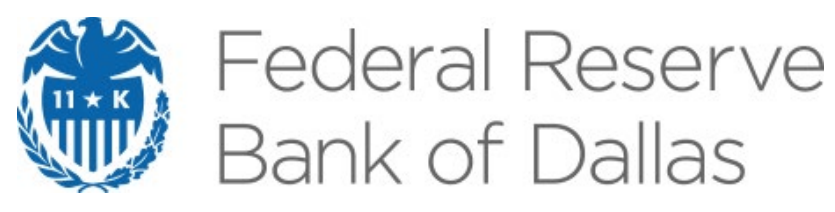

\title{
The Local Fiscal Multiplier of Intergovernmental Grants: Evidence from Federal Medicaid Assistance to States
}

Seth Giertz and Anil Kumar

Working Paper 2112

September 2021

Research Department

https://doi.org/10.24149/wp2112

Working papers from the Federal Reserve Bank of Dallas are preliminary drafts circulated for professional comment. The views in this paper are those of the authors and do not necessarily reflect the views of the Federal Reserve Bank of Dallas or the Federal Reserve System. Any errors or omissions are the responsibility of the authors. 


\title{
The Local Fiscal Multiplier of Intergovernmental Grants: Evidence from Federal Medicaid Assistance to States*
}

\author{
Seth Giertz ${ }^{\dagger}$ and Anil Kumar ${ }^{\ddagger}$
}

September 2021

\begin{abstract}
Advocates of Medicaid expansion argue that federal Medicaid assistance to states fosters economic activity, generating positive local multiplier effects. Furthermore, during economic downturns, Congress regularly tweaks federal match rates for state Medicaid spending - including during the COVID-19 public health emergency - in order to assist states. Despite heavy reliance on Medicaid funding formulas, identifying the economic effect of these federal transfers has proved challenging. This is because federal Medicaid assistance (to states) is endogenous, since funding levels are correlated with unobserved factors driving state economic activity. To address this concern, we construct an instrument based on a slope discontinuity in the federal matching rate for state Medicaid spending. Using state-level panel data from 1990 to 2013, we find that federal Medicaid assistance does stimulate economic activity, but the implied cost per job created is quite high and the multiplier is well below 1. Despite modest economic effects over the entire sample period, we find that federal Medicaid assistance provided powerful fiscal stimulus to states after the Great Recession when the implied multiplier shot up to 1.5.
\end{abstract}

Keywords: Fiscal Multiplier, Fiscal Stimulus, Medicaid Matching Grants

JEL Numbers: C31, E62, I38, H31

\footnotetext{
*We thank Jason Seligman, conference participants at the National Tax Association's 112th Annual Conference on Taxation, and the WEAl's $96^{\text {th }}$ Annual Conference for helpful comments. Views expressed here are those of the authors and do not necessarily reflect those of the Federal Reserve Bank of Dallas or the Federal Reserve System or the University of Texas at Dallas.

†Seth Giertz, Department of Economics, The University of Texas at Dallas, seth.giertz@utdallas.edu.

${ }^{\ddagger}$ Anil Kumar, Research Department, Federal Reserve Bank of Dallas, anil.kumar@dal.frb.org.
} 


\section{Introduction}

Medicaid accounted for more than half of the nearly $\$ 800$ billion the federal government sent to state and local governments as intergovernmental grants in $2019 .{ }^{1}$ It is by far the largest and the fastest growing means-tested transfer program in the U.S, constituting 9.4 percent of federal expenditures. The Congressional Budget Office (CBO) projects that federal Medicaid spending as a share of GDP will increase by 74 percent, from 1.9 percent of GDP in 2018 to 3.3 percent of GDP in $2047 .^{2}$ The program is funded jointly by the federal and state governments, with the federal government reimbursing 50-74 percent of states' Medicaid costs in the form of matching funds based on the Federal Medical Assistance Percentage (FMAP) formula. Furthermore, Congress often passes temporary increases to FMAP in order to send more money to states during periods of economic stress. This includes an across-the-board increase to FMAP of 6.2 percentage points in the Families First Coronavirus Response Act (FFCRA) to extend through the COVID-19 public health emergency.

Research, as well as media reports, points to positive spillovers from federal Medicaid assistance (henceforth FMA) on state employment and economic activity. ${ }^{3}$ For example, in separate 2014 reports, the President's Council of Economic Advisors touted the effect of federal matching grants on state economies, arguing that the stimulative effects from temporary increases to federal Medicaid reimbursement rates in the 2009 economic stimulus package created or saved millions of jobs. ${ }^{4}$ Despite such triumphant pronouncements, there are surprisingly few estimates of the state-level multiplier from FMA, which has been in operation since 1965. Estimating its impact on local economic activity is a challenge because state Medicaid spending, by construction, is inherently endogenous and almost surely driven by local economic conditions.

Among the few papers to explicitly focus on FMA, Chodorow-Reich et al. (2012) and Chodorow-Reich (2019) estimated the local multiplier of a temporary increase in FMAP transfers under the American Recovery and Reinvestment Act (ARRA) during 2009-2010 and addressed

\footnotetext{
${ }^{1}$ See https://www.gao.gov/federal-grants-state-and-local-governments.

${ }^{2}$ The pace of growth accelerated further with the Medicaid expansion under the Affordable Care Act (ACA). The CBO estimates that as much as 21 percent of the overall Medicaid funding in 2019 will support adults made eligible because of the ACA Medicaid expansion.

${ }^{3}$ For example, see Kliff (2012) in The Washington Post.

${ }^{4}$ In the other case, they touted prospective gains to state economies from increased federal grants associated with expanding Medicaid. Here, they argued that federal Medicaid spending raises worker productivity partly by improving the health of recipients. This notwithstanding, empirical size of local multipliers is far from clear, as it depends on a number of factors, including how the spending is structured, how it is financed, on macroeconomic conditions, and on possible monetary policy responses.
} 
the endogeneity by using state-level lagged (pre-recession) Medicaid spending as an instrument. As noted in Chodorow-Reich et al. (2012), a potential concern with the lagged spending instrument is that it still depends on state Medicaid spending rules which may be correlated with the severity of the downturn.

We propose a new instrument to overcome endogeneity concerns and, in so doing, make three contributions to this literature. First, our instrument is based on a long-standing discontinuity in the slope of FMAP with respect to relative per capita income (RPCPI), where RPCPI is defined as a moving average of lagged state per capita personal income divided by the corresponding measure for the US as a whole. FMAP covers a declining share of state Medicaid spending as RPCPI increases before reaching a floor of 50 percent when RPCPI exceeds 1.054, which imparts the slope discontinuity (see Figure 1). We show that the discontinuity in the FMAP schedule also induces a discontinuity in per capita federal matching dollars states receive - something also found by Leung (2016) in addressing a different question. Second, rather than estimate the effect of bonus FMAP transfers to states often made during economic downturns, we are the first to estimate the local multiplier from traditional FMAP-based transfers. And third, our use of a long panel of statelevel data from 1990 to 2013 allows us to estimate dynamic, time-varying, and long-term estimates of the multiplier, spanning the range of the business cycle.

To preview key findings, our preferred IV estimates indicate that FMA had a modest positive multiplier over the period 1990-2013. For example, when restricting our sample to a narrow band surrounding the kink created by the FMAP discontinuity, we find that an additional $\$ 100,000$ per year in FMA yields about 0.75 jobs over three years. This implies a statistically insignificant employment impact of 0.25 job-years at a cost per job of $\$ 400,000$ (in 2016 dollars) ${ }^{5}$ However, these aggregate results mask substantial heterogeneity across subsets of years. Over the 1990s, we consistently find that the FMA multiplier was very small with point estimates below 0.25. Based on confidence intervals, we can rule out multiplier larger than 0.33 when restricting the sample to a narrow bandwidth surrounding the slope discontinuity; for the full sample, we can rule out multipliers larger than 0.66. However, the estimated multiplier is larger after 2000, reaching 1.5 after the Great Recession with an associated cost per job year of $\$ 81,000$. Thus, our

\footnotetext{
${ }^{5}$ Alternative specifications for the full time period sometimes yield a much larger, but still very small, jobs multiplier. For example, without bandwidth restrictions, our full period estimate is a multiplier of 0.54 at a cost of over $\$ 200,000$ per job. It should also go without saying that intergovernmental transfers to states serve important purposes beyond creating jobs. And, policymakers will want to consider these other benefits, in addition to multiplier effects.
} 
multiplier estimates for 2008-2010 are similar, although somewhat smaller, than those reported by Chodorow-Reich et al. (2012) for the same time period. They estimated a cost of $\$ 26,000$ (in bonus FMAP payments) in order to create one job, implying a multiplier of around $2 .^{6}$

Our main identifying assumption is that the FMAP discontinuity (with respect to RPCPI) is uncorrelated with either local economic conditions or state Medicaid rules. Thus, we assume that states do not pursue perverse economic policies in order to manipulate their Medicaid match rate, nor do they have enough influence to lead Congress to manipulate the formula. However, states may have a good idea as to what their match rate will be when making policy decisions regarding Medicaid. Thus, a state's location with respect to the FMAP slope discontinuity may influence its fiscal policy, including spending on Medicaid.

The remainder of the paper is organized as follows. Section 2 connects our work with the literature on multipliers from intergovernmental grants; section 3 describes the data and details the proposed FMAP instrument; section 4 presents the econometric specification and discusses identification; section 5 reports the results and section 6 concludes.

\section{Incentive Effects from FMAP and Literature on Local Multipliers}

The federal government subsidizes state Medicaid spending via matching grants. The match rate varies across states and over time, but for a state (in a given year) the rate is fixed. ${ }^{7}$ In other words, the match rate is based on lagged economic variables and is independent of state Medicaid rules. We examine the effects of an increase to a state's Medicaid match rate, which increases the size of the matching grant sent to the state, on state economic activity. The incentive effects to states flow through two different channels. The first channel is an inframarginal effect, where the state receives more federal dollars (than it would have otherwise) for Medicaid spending than it would have absent an increase to its match rate. This inframarginal effect is akin to a lumpsum or unrestricted grant to the state. The second channel is a marginal (or behavioral) effect, where the state has an incentive to increase Medicaid spending as a result of the increased match rate. Increased federal spending from this second channel contributes directly to an expansion of

\footnotetext{
${ }^{6}$ In another paper, Chodorow-Reich (2019) also uses cross-sectional variation to identify stimulative effects of total ARRA spending. Here, he emphasizes a jobs multiplier of between 1.8 to 2.3 per $\$ 100,000$ in additional federal grant at a cost per job year of $\$ 50,000$ with an implied multiplier of 1.5 .

${ }^{7}$ In some cases, states may have a different match rate for certain groups, such as those covered by the ACA Medicaid expansion.
} 
Medicaid. In contrast to the inframarginal effect, to benefit from the marginal effect, the state must divert funds from other activities towards Medicaid in exchange for increased federal grants. ${ }^{8}$ The effects of grants to states will depend partly on the relative importance of these two different channels and thus on the policy under evaluation.

\subsection{The Inframarginal Channel}

In examining the effects from the 2009 recovery act (i.e., ARRA), the inframarginal channel is of primary importance. This is because ARRA temporarily increased Medicaid match rates to states, with bigger increases for states that experienced greater increases in their unemployment rates. (Penalties prevented states from cutting Medicaid while the FMAP bonus was in effect.) As a result, extra federal grants were almost entirely de facto lump sum grants to states. Chodorow-Reich (2019) reviews a number of papers examining the stimulative effects of the temporary FMAP increase, as well as producing new estimates. ${ }^{9}$ Chodorow-Reich refers to these as "cross-sectional" multipliers because they measure effects of targeted spending in states or localities, and because cross-sectional variation in treatment is used to identify effects. Identification in these studies is generally based on instruments constructed from pre-recession variables.

Chodorow-Reich employs a cross-sectional approach where the dependent variable is average annual employment (or output) growth over the period of the act (normalized by the state's working age population). This variable is regressed against a vector of state economic conditions, and ARRA outlays, with these variables normalized (where relevant) in the same manner.

He then compares estimates using alternative instruments for ARRA outlays. With respect to job years per a $\$ 100,000$ increase in spending, estimated multipliers from the four sets of instruments range from 1.8 to 2.2, with a mean of 2.1. Recalibrating these numbers, based on output per worker, yields a mean output multiplier of 1.9. This is in line with seven other papers that he considers, where the mean output multiplier is 2.1 - and 1.8 when excluding two studies examining permanent, rather than transitory, spending increases.

\subsection{The Marginal Channel}

\footnotetext{
${ }^{8}$ Note that, the first (inframarginal) channel could also result in some increased Medicaid spending.

${ }^{9}$ Also see Wilson (2012) and Conley and Dupor (2013) among papers estimating multipliers from ARRA.
} 
On the other hand, in analyzing the Medicaid expansion following the 2010 Affordable Care Act (ACA), the marginal channel would be the only relevant factor. For the most part, under the ACA Medicaid expansion, the federal government offered to cover new groups with, at least initially, a 100-percent match rate - and did not provide more funding for groups previously covered by Medicaid. Thus, added funds from ACA would represent federal support for new Medicaid spending and not an unrestricted grant. While supporters of Medicaid expansion argue that it would be a boon to states, there is little hard evidence to support (or to counter) this contention.

\subsection{Blended Approach}

As an alternative to these two examples, consider an increase (or decrease) to the match rate for a state, where the increase (or decrease) applies both to preexisting state Medicaid spending, as well as to increases in state Medicaid spending. This "blended" case is also policy relevant and is the focus of our analysis. For example, in its 2018 budget options volume, the Congressional Budget Office analyzed the federal revenue implications of three options that would modify Medicaid matching grants to states. One of these options involved removing the 50-percent floor on the federal match rate, which binds for some rich states, i.e., they examine the effects of removing the slope discontinuity. Our analysis evaluates the broader policy implications of just such a policy change.

With respect to methodology, our paper has much in common with Lundqvist et al. (2014) who estimate the effect of intergovernmental grants on employment. Like us, their identification strategy centers on a slope discontinuity in the generosity of intergovernmental grants. Unlike us, their focus is not on Medicaid match rates, but rather on a program in Sweden. Their main dependent variable is the per capita number of full-time equivalent employees (by municipality) and their key dependent variable is per capita intergovernmental grants received. As an instrument, they use a dummy variable that indicates whether the municipality is below or above the outmigration threshold that determines eligibility for supplemental internal grants. In contrast to many US-based ARRA papers, Lundqvist et al. report almost no effect of grants on employment.

\section{Data and Instruments}




\subsection{Sate-Level Panel, 1990-2013}

Our analysis is based on panel data for U.S. states spanning years 1990-2013. The primary dependent variable - per capita jobs - is based on non-farm payroll employment data from the Current Establishment Statistics (CES) program of the Bureau of Labor Statistics (BLS). We calculate per capita jobs for each state by normalizing the annual average of monthly non-farm payroll employment from the BLS by state population from the Bureau of Economic Analysis (BEA). We focus on jobs because it provides the most reliable estimate of economic activity at the state level and is measured more accurately than more comprehensive measures such as GDP, which are known to contain significant measurement error at the state level.

Data on state Medicaid expenditures are included in the Centers for Medicare \& Medicaid Services (CMS) data files on "State Health Expenditures by State of Provider." For each state, we use FMAP to compute our key explanatory variable, federal assistance to states for Medicaid, also converted to per capita terms. FMAP data are from the U.S. Department of Health and Human Services (HHS) and data on state and US per capita personal income are from the Bureau of Economic Analysis (BEA). Federal Medicaid dollars and other monetary variables, such as GDP, are expressed in 2016 prices. Data on demographic covariates included in various specifications come from the Current Population Survey (CPS) of the Census Bureau. Table 1 presents summary statistics for key variables.

\subsection{Discontinuity in the Federal Medicaid Funding Formula}

Recall that our goal is to estimate the effect of an exogenous change to FMA on state employment. However, state employment and FMA are simultaneously determined, since both are closely correlated with state PCPI. A floor in the FMAP funding formula implies no relationship between PCPI and FMA once the floor is reached. Here, we provide background on the determinants of federal funding for Medicaid and establish that the floor in the FMAP formula is mirrored by a floor in per capita FMA.

The FMAP formula governs the share of total Medicaid expenditures (appropriated by states) paid by the federal government. The formula is given by

$$
F M A P_{s t}=\min \left(\max \left(0.5,1-0.45 *\left(\frac{\overline{P C P I}_{s t}}{\overline{P C P I}_{t}^{U S}}\right)^{2}\right), 0.83\right)
$$

Central to FMAP is the relationship between state and U.S. per capita personal income (PCPI). In 
equation (1), $\overline{P C P I}_{s t}$ and $\overline{P C P I}_{t}^{U S}$ represent a 3-year moving averages of PCPI in year $t$ for state $s$ and the U.S., respectively. For year $t$, PCPI is calculated based on income from years $t-3, t-$ 4 , and $t-5$. The formula implies that FMAP is 55 percent if the lagged measure of state PCPI equals the U.S. average (USPCPI). Also note that, above the floor, FMAP is inversely related to the RPCPI, i.e., $\frac{\overline{P C P I}_{s t}}{\overline{P C P I}_{t}^{U S}}$, The FMAP floor of 50 percent imparts a discontinuity in the match rate when the RPCPI reaches 1.054. In other words, FMAP is greater than 0.5 if the RPCPI is below 1.054 and FMAP equals 0.5 if the ratio exceeds 1.054. In addition to a floor, FMAP also includes a ceiling of 83 percent. However, this ceiling almost never binds.

The discontinuity in per capita FMA, with respect to state PCPI relative to the US, is used to construct our instrument. This is discussed in greater detail in the following section. Here, we present Figure 2 in order to establish that the FMAP formula does, for a given level of state Medicaid spending, impart a slope discontinuity in the level of per capita FMA. Figure 2 represents a stylized state with Medicaid expenditures equal to the 2018 national average of $\$ 1,811$ per capita. The figure is constructed such that, while per capita Medicaid expenditures is held constant, per capita FMA varies across a range of actual PCPI ratios observed for the 50 U.S. states.

Figure 2 shows that the discontinuity in the FMAP formula does in fact mirror the discontinuity in per capita FMA. For PCPI ratios exceeding 1.054, the grant hits a floor of $\$ 906$ per capita. The difference between this floor and the near-linear relationship can be viewed as an exogenous bonus to states that hit the floor. This bonus exceeds $\$ 906$ per capita for the very richest states, since, absent the floor, the very richest states would have a negative FMAP. Note that FMA without a floor would be poorly suited for isolating the effects of federal grants to states. Without the floor, FMA is declining at a smooth rate with respect to state PCPI which is closely correlated with both the need and the ability of states to finance Medicaid. Thus, the endogeneity cannot be disentangled. However, by comparing the relationship between state economic activity and deviations between actual FMA and counterfactual FMA (i.e., FMA in the absence of the floor), we can isolate the causal effects of the grants on state economic activity.

FMAP has remained largely unchanged since its inception and states have no control over the formula. While the FMAP formula is determined by (lagged) economic activity, the discontinuity in the formula is exogenous with respect to policy or economic considerations. As detailed in Mitchell (2020), there have been some instances when FMAP has deviated from the formula. For example, FMAP for DC is set at 70 percent regardless of how its per capita income 
compares to that of the nation. Also, as part of the ACA, FMAP increased to 100-percent for newly eligible Medicaid enrollees in states that opted for Medicaid. FMAP was also increased in 20032004 to assist states during a slow economic recovery. During the Great Recession, ARRA permitted FMAP to deviate from the usual formula through 2010, with deviations tied to the state unemployment rates. There were also temporary adjustments for Alaska, Michigan, and Louisiana (due to Hurricane Katrina).

In addition to Medicaid funding, FMAP is also used for some much smaller programs: Guardianship Assistance, Child Care and Development Block Grant, Child Care mandatory and matching funds of the Child Care and Development Fund, Foster Care- Title IV-E, Adoption Assistance, and the phased down state contribution or the clawback for Medicare-Part D. Additionally, the Children's Health Insurance Program (CHIP) uses enhanced FMAP (E-FMAP) which equals $F M A P+0.3 \times(1-F M A P)$ with a cap of 85 percent. Thus E-FMAP also has a discontinuous slope with respect to RPCPI at the same place as FMAP.

\section{Econometric Framework and Identification}

\subsection{Econometric Framework}

To estimate impulse responses with panel data we follow the local projections (LP) approach with instrumental variables employed in influential work on government spending multipliers by Ramey and Zubairy (2018). ${ }^{10}$ The LP approach is an alternative to vector autoregression (VAR), where a system of equations is estimated, and then impulse responses are produced by, for example, shocking the error term of one of the equations and then projecting forward. LPs are simpler in that they do not require multiple equations. ${ }^{11}$ Jordà notes additional advantages of the LP approach, stating that LPs "are robust to misspecification of the data generating process; and they easily accommodate experimentation with highly nonlinear specifications that are often impractical or infeasible in a multivariate context." LPs are based on "projections local to each forecast horizon." By contrast, Jordà demonstrates that VAR-based

\footnotetext{
${ }^{10}$ LP approach was originally proposed in Jordà (2005).

${ }^{11}$ While a system of equations is not required, more than one equation may be required, if an instrumental variables approach is used to address endogeneity issues.
} 
impulse responses are more susceptible to biases as the forecast period increases - for example, resulting from the linear extrapolation of nonlinear phenomena.

Following Ramey and Zubairy (2018) and Chodorow-Reich (2019), the h-period impulse response of FMA dollars on employment can be estimated using the following specification:

$$
y_{s, t+h}-y_{s, t}=\beta_{1}^{h} F M A_{s t}+\lambda_{1}^{h} \widetilde{R P C P} I_{s t}++\gamma^{h} X_{s t}+\mu_{t}^{h}+\alpha_{s}^{h}+u_{s, t+h},
$$

where $y_{s, t+h}-y_{s, t}$ is the h-period change in per capita jobs for state $s$ in year $t+h ; F M A_{s t}$ is the state's federal reimbursement for Medicaid spending, in per capita terms and based on FMAP. To exploit the FMAP slope discontinuity as a source of identification, we augment the conventional specification with the normalized assignment/running variable $(\widetilde{R C P I}=R P C P I-$ 1.054), i.e., normalized $R P C P I$ that equals zero when $R P C P I=1.054 ; \mu_{t}^{h}$ are year effects; and $X_{s t}$ consists of other controls that may be correlated with both $F M A_{s t}$ and $y_{s, t+h}-y_{s, t} ; \alpha_{s}^{h}$ is an unobserved state effect that may be correlated with other covariates. The LP methodology involves regressing $y_{s, t+h}-y_{s, t}$ on the right-hand side variables of (2) for a set of time horizons, $h$. In this LP framework, $\beta^{h}$ captures the impulse response of one unit of initial shock to $F M A_{s t}$ on the outcome variable in period $h$.

Guided by econometric specifications in Chodorow-Reich et al. (2012) and Ramey and Zubairy (2018), we include a set of variables $\left(X_{s t}\right)$ in our baseline specification to control for the economic and demographic composition of states. These variables include the share of state employment that is unionized, share of manufacturing in state GDP, state population to control for states' size, and per capita real GDP. These variables are lagged one year to avoid endogeneity. To account for trends in economic activity that may be correlated with $F M A_{s t}$. we include year affects. We additionally control for state-level demographic covariates: the share of state population: over age 65; female; white non-Hispanic; black; Hispanic; with a high school diploma; and those with college education. We also show that the estimates from our baseline specification are robust to an expanded set of covariates that include Census division dummies and division by year effects. And finally, while we do not include lags of the dependent variable in our baseline specifications due to well-known problems with lagged dependent variables in unobserved effects panel data models, we show that the results are highly robust to inclusion of such lags.

As discussed in Ramey and Zubairy (2018), in a dynamic environment, the multiplier has many definitions depending on the timing and scope of output response and/or the spending shock. We estimate the cumulative version of the multiplier - the response of $H$-year integral of change 
in per capita jobs to the $H$-period integral of per capita $F M A_{s t}$, estimating the following specification:

$$
\sum_{h=0}^{H}\left[y_{s, t+h}-y_{s, t}\right]=\beta_{1}^{H} \sum_{h=0}^{H} F M A_{s t+h}+\lambda_{1}^{H} \widetilde{R P C P} I_{s t}+\gamma^{H} X_{s t}+\mu_{t}^{H}+\alpha_{s}^{H}+u_{s, t+H},
$$

where $\beta_{1}^{H}$ denotes the $H$-year cumulative jobs impact. ${ }^{12}$ We show that our estimate of the implied per-year jobs response to per-year $F M A_{s t}\left(\right.$ i.e., $\beta_{1}^{H} / H$ ) is remarkably robust to the horizon $H$, so we set $H$ to 3 in most specifications, unless indicated otherwise. ${ }^{13}$ Noting that $\sum_{h=0}^{H} F M A_{s t+h}$ is in $\$ 100,000$ per capita, we calculate the implied cost per job year as $\$ 100,000 /\left(\beta_{1}^{H} / H\right)$ and, following the suggestion in Chodorow-Reich (2019), also back out the implied multiplier by dividing an estimate of output per job with the implied cost per job. We estimate output per job as the average GDP across states divided by the average nonfarm payroll jobs over the estimation sample, which yields an output per job of $\$ 108,700$ in 2016 prices.

As previously noted, $\sum_{h=0}^{H} F M A_{s t+h}$ is likely correlated with $\alpha_{s}^{h}$ and $u_{s, t+h}$, making OLS estimates, with or without fixed effects, biased and inconsistent. In addition to being correlated with a variety of economic and demographic factors, FMA is also both a cause and an effect of state economic activity. For example, all else equal, lower-income states, with slower income growth, will tend to receive more FMA than more prosperous states. Furthermore, as noted in Chodorow-Reich et al. (2012), $\sum_{h=0}^{H} F M A_{s t+h}$ is almost surely correlated with intricacies of statespecific Medicaid spending rules, which end up in $u_{s, t+H}$ because Medicaid spending tends to be countercyclical. And if such state-specific Medicaid rules are serially correlated then even the use of lagged Medicaid spending would not mitigate the endogeneity problem (Bellemare et. al., 2017).

Our instrument is motivated by the Fuzzy Regression Kink Design (RKD) approach proposed by Card et al. (2015) and employed by Lundqvist et al (2014) in the context local multipliers. The discontinuity in the slope of $\sum_{h=0}^{H} F M A_{s t+h}$ with respect to the assignment/running variable RPCPI is driven by the well-known discontinuity in the FMAP formula. The discontinuity occurs when RPCPI equals 1.054: FMAP is greater than 0.5 if $R P C P I$ is under 1.054 and FMAP equals 0.5 if RPCPI exceeds 1.054. Now let Above denote an indicator

\footnotetext{
12 The cumulative multiplier specification used here is almost identical to Fieldhouse, Mertens and Ravn (2018).

${ }^{13}$ Note that $\beta_{1}^{H}$ in the numerator of $\beta_{1}^{H} / H$ is $\beta_{1}$ with superscript $H$ and should not be confused with power $H$.
} 
variable, $1(\widetilde{R P C P} I>0)$, for RPCPI being above the FMAP slope discontinuity at 1.054 . Then for the local linear specification. the first-stage relationship can be written as: ${ }^{14}$

$$
\sum_{h=0}^{H} F M A_{s t+h}=\gamma_{1}^{H} \widetilde{R P C P} I_{s t}+\eta_{1}^{H}\left[\widetilde{R P C P} I_{s t} \times A b o v e\right]+\delta^{H} X_{s t}+\lambda_{t}^{H}+\gamma_{s}^{H}+v_{s t+H}
$$

For a linear polynomial, the estimation collapses to a simple regression of $\sum_{h=0}^{H} F M A_{s t+h}$ on $\widetilde{R P C P I}$, the interaction term $\widetilde{R P C P I} \times A b o v e$, and other controls. The coefficient on the linear interaction term, $\eta_{1}$, measures the difference in slope of $F M A_{s t}$ with respect to RPCPI at the FMAP slope discontinuity $(\widetilde{R C P} I=0)$. Given well-known concerns with higher order polynomial in RD/RKD designs with small sample size as ours (Gelman and Imbens, 2018; Pei et. al., 2021), we estimate local linear regressions, omitting higher order polynomials of $\overline{R P C P I}$ and $\widetilde{R P C P I} \times$ Above. In the Fuzzy RKD case, $\overparen{R P C P I} \times$ Above can be seen as an instrument and we treat it as such in the remainder of this paper. If it is indeed a valid instrument, then for the linear polynomial case, the second stage becomes:

$$
\sum_{h=0}^{H}\left[y_{s, t+h}-y_{s, t}\right]=\beta_{1}^{H} \sum_{h=0}^{H} \widetilde{F M A_{s t+h}}+\beta_{3}^{H} R \widetilde{P C P I}_{s t}+\gamma^{H} X_{s t}+\mu_{t}^{H}+\alpha_{s}^{H}+u_{s, t+H}
$$

In both (4) and (5), we assume that conditional on a rich set of covariates the unobserved state effects are uncorrelated with the instrument and $\sum_{h=0}^{H} F M A_{s t+h}$, respectively, and use pooled OLS.

As discussed at length later, this is because the instrument has little time variation within states. This is consistent with the recent literature on geographic cross-sectional multiplier, which is identified primarily off of cross-sectional variation (Chodorow-Reich et. al., 2012; Lundqvist, Dahlberg, and Mörk, 2014; Suárez, Serrato, and Wingender, 2016; Chodorow-Reich, 2019). ${ }^{15}$ We recognize that the presence of state-specific unobserved effect would induce serial correlation in the composite error term $\alpha_{s}^{h}+u_{s, t+h}$ - a concern that we address by clustering all standard errors at the state level. Additionally, we throughout estimate regressions unweighted by variables representing states' size as the objective is to get causal estimates of the jobs impact of FMA rather than nationally representative quantities.

\footnotetext{
14 Note that using normalized $R P C P I$ in this equation is simply for convenience, as the regression is numerically equivalent to one in which $\widehat{R P C P I}$ is replaced with $R P C P I$.

${ }^{15}$ See Nakamura and Steinsson (2014) for an alternative empirical approach using panel data.
} 


\subsection{Identification}

The key identifying assumption is that the instrument, $\overrightarrow{R P C P I} \times$ Above, is correlated with $F M A_{s t}$, it has no direct correlation with $y_{s, t+h}$. In other words, the location of the FMAP discontinuity is effectively exogenous and states are unable to manipulate their location around the discontinuity. The ability to manipulate their location would imply that the slope discontinuity itself is endogenous and therefore an invalid instrument. This can be informally tested by examining whether the density of the assignment variable ( $R P C P I)$ evolves continuously around the discontinuity in the FMAP formula.

Figure 3 plots the density of $R P C P I$ around the discontinuity and shows no statistically significant difference in the densities at the discontinuity - i.e., there is no statistical evidence of manipulation (McCrary, 2008). Moreover, the log difference in height of the two densities at the discontinuity is 0.29 with a standard error of 0.16 , which is not significant at the 5 percent level. This is hardly surprising, as RPCPI for state $s$ in year $t$ is calculated using personal income data from years $t-3, t-4$, and $t-5$, which is to say that they are several years old.

The primary identification condition, that $\overparen{R P C P} \times$ Above is uncorrelated with the error term $u_{s, t+h}$, remains fundamentally untestable in the just identified case. However, we do conduct an informal test for the discontinuity in slopes (with respect to the running variable) in other covariates potentially correlated with economic activity. Table 2 reports p-values on the test of significance of $\widetilde{R C P I} \times$ Above for several covariates, including two state-level spending measures - per capita TANF spending and per capita non-Medicaid spending. P-values along with significance indicators are reported for different bandwidths around the discontinuity. Importantly, for the two non-Medicaid spending measures reported in in the first two rows, the null hypothesis that no discontinuity exists (at the location of the discontinuity in the FMAP formula) cannot be rejected. Overall, Table 2 shows that the presence of a significant slope discontinuity among covariates is an exception rather than the norm. A few covariates out of multiple being tested would turn out to be significant simply by chance. When we adjust the p-values for multiple testing, none of them remain significant. Nonetheless, as an extra precaution and to guard against potential correlations with any such covariates, we control for a large set of covariates in our main results (presented in the next section). 
Even as Table 2 shows little evidence of slope discontinuity across other covariates, Figure 4 shows visual evidence of discontinuity in the slopes with respect to RPCPI for both the endogenous variable (FMA) and the outcome variable (jobs).

\section{Results}

\subsection{Full sample results}

Table 3 includes regression results that examine the validity of our identifying assumptions. We control for year effects as well as state-level economic and demographic covariates (including $\overrightarrow{R P C P I}$ ) for the full sample from 1990 to $2010 .{ }^{16}$ While the instrument, $\overrightarrow{R P C P I} \times$ Above, is uncorrelated with non-Medicaid spending in column (1), it is correlated with Medicaid spending in column (2), with an estimated coefficient that is significant at 10-percent level. Furthermore, the first-stage estimated coefficient of 0.052 , reported in column (3), shows a strong statistically significant relationship with the endogenous variable - federal Medicaid dollars $\left(\sum_{h=0}^{3} F M A_{s t+h}\right)$. Column 4 of Table 3 presents the reduced form coefficient from regressing the key outcome variable, $\sum_{h=0}^{H}\left[y_{s, t+h}-y_{s, t}\right]$, on the instrument along with other controls. The reduced-form coefficient of 0.078 is also precisely estimated. By definition, the IV estimate of 1.5 equals the ratio of the reduced form coefficient to the first-stage coefficient. That is, a $\$ 100,000$ injection of FMA in states through the traditional FMAP formula is associated with 1.5 added jobs over 3 years, for a per-year job estimate of around 0.5 , at a cost per job of nearly $\$ 200,000$ over the entire sample period from 1990 to 2010.

Continuing with the full sample results, Table 4 compares IV estimates with simple OLS estimates and examines the sensitivity of the estimates to inclusion of state fixed effects in our IV specifications. The OLS estimate in column (1) is consistent with downward endogeneity bias. This estimate more than doubles in size when accounting for state fixed effects in column (2). This suggests substantial omitted variable bias with simple OLS due to unobserved state-level characteristics. IV estimates from column 3, without fixed effects, are similar to fixed effects OLS estimates, suggesting that the instruments help mitigate the bias from omitted state-specific factors. The first stage Kleibergen-Paap rk Wald F-statistic of 9.06, reported in column (3), shows that the

\footnotetext{
${ }^{16}$ Note that, while our data extend to 2013 , the latest base year used in our analysis is 2010 , since some variables include information from the three years following the base year.
} 
instrument is sufficiently strong and the null of weak instruments is strongly rejected, with an associated p-values of 0.004 .

However, IV estimates are imprecise when state fixed effects are included in column (4) and are no longer reliable as the first stage F-statistic drops to a level that suggest (very) weak instruments. This is not entirely surprising because the instrument, $\widetilde{R P C P} I \times$ Above, exhibits little time-series variation within states. This is because 80 percent of states have RPCPI that is always either above or below the FMAP discontinuity (at 1.054) for the entire sample period. Even RPCPI has limited within-state variation over time - the within standard deviation is just 18 percent of the overall standard deviation. Given the lack of within variation, the fixed effects IV models are not very informative. Therefore, like Chodorow-Reich et al. (2012), Chodorow-Reich (2019) and Lundqvist et al. (2014), identification in our case relies primarily on cross-sectional variation in the instrument, relying on the assumption that conditional, on an extensive set of covariates, $\widetilde{R P C P I} \times$ Above is uncorrelated with any remaining unobserved shocks to current or future economic conditions.

Table 5 assesses the robustness of our estimates to the inclusion of covariates, providing insight into the degree of omitted variable bias in our IV estimates. Column (1) starts with the most parsimonious specification with $\widehat{R P C P} I$ as the only control in the IV regression. This barebones specification yields a precise estimated coefficient of 0.87 . We see a decline in the estimate with the inclusion of year effects in column (2), suggesting that other macroeconomic drivers of economic activity absent from column (1) were positively correlated with FMA. The addition of other state-level economic and demographic covariates in columns (3) and (4) does have an important effect on the size of the estimated coefficient, underscoring the need for their inclusion in the baseline specification. To account for any unobserved shocks by region or by region and time, column (5) include Census division dummies and column (6) also interacts these dummies with year fixed effects. Finally, column (7) shows that the estimates are robust to inclusion of three lags of job growth. From columns (4) to (7), coefficient estimates increase modestly in size but are largely stable; therefore, the model in column (4) is our default specification unless otherwise indicated otherwise.

\subsection{Sensitivity over time}


Sensitivity of estimates over time is presented in Table 6 with the column (1) reproducing the full sample results from the baseline specification. Column (2) restricts the sample to the 1990s, which reduces the coefficient to just a half of the full sample estimates in column (1) and uncertainty jumps considerably. The implied cost per job doubles from $\$ 200,000$ for the full sample to $\$ 400,000$ for the 1990 s with the implied multiplier declining from 0.54 to 0.25 . FMA appears to have done very little to stimulate state economies during the 1990s expansion. However, the effect for the early 2000s was much bigger with the coefficient jumping to 2.2 in column (3). Even this much higher estimate implies a still modest multiplier of 0.83 . Column (4) suggests that the stimulus from FMA to states was strongest in the aftermath of the Great Recession from 20082010. While the estimates are highly imprecise-likely due to weak instruments, the implied multiplier exceeds 1 .

\subsection{Robustness to bandwidth}

So far, we have used the entire range of the running variable, $R \widetilde{R C P} I$, which extends from -0.4 to 0.4 on either side of the FMAP discontinuity-i.e., for a symmetric bandwidth of 0.4 . It is well known that estimates based on RDD/RKD are more credible for small bandwidths around the discontinuity. As the bandwidth is expanded, the possibility of unobserved heterogeneity rises. We examine the sensitivity of our estimates to bandwidths in Table 7, which reports estimated coefficients for a set of 4 bandwidths, ranging from 0.1 to 0.4 .

Results for the smallest bandwidth, 0.1 , appear to suffer from weak instruments, as the first stage F statistic on the instrument is small. In terms of instrument strength, estimates for the 0.2 bandwidth appear reliable across all periods, though, given small sample sizes, precision is still a concern. While the results are clearly sensitive to the bandwidth, the overall pattern across periods appears consistent with the full sample results with 0.4 bandwidth in column (4) - the estimate is small and imprecise in the 90's and increases in the 2000's, though the implied multiplier remains modest for the pre-Great Recession period. For the post-Great Recession period, only the estimate with 0.2 bandwidth appears reliable with a first stage F statistic of 5.49 and an associated p-value of 0.06 . Because there is potential for more bias in estimates from larger bandwidths, we focus mainly on results from employing the 0.2 bandwidth for discussing the implications of our estimates. 


\subsection{Discussion}

Implied multipliers mirror estimated coefficients discussed earlier-they are small in the 1990s, larger in the 2000s, and quite substantial only during the three years after the Great Recession, when the multiplier is 1.5 with an implied cost per job of $\$ 81,000$ - close to ChodorowReich's (2012) estimates for the same period. Given the uncertainty around point estimates, the multipliers have fairly wide confidence intervals, which we present in Tables 8 , for the full sample with 0.4 bandwidth in panel $\mathrm{A}$ and for the narrower 0.2 bandwidth in panel $\mathrm{B}$.

Focusing on 0.2 bandwidth and the 1990-2010 period, the upper bound of the multiplier in column (1) is 0.64 , so we can rule out large multipliers from FMA - a dollar of spending led to less than a dollar of output. We know that estimates using data from 1990 to 2010 mask substantial heterogeneity across years. As already noted earlier, the multipliers were small during the 90s expansion and so is their upper bound presented in panel B of Table 8. Between 2000 and the Great Recession, the multiplier had an upper bound of around 1. Point estimates are largest following the Great Recession, where we cannot rule out very large multipliers as high as 3.5. Figure 5 plots point estimates and confidence intervals for the model with 0.2 bandwidth.

Cost per job estimates reported in Appendix Table 1 reveal a pattern analogous to that for the multiplier estimates. Using data for all years the estimated cost per job is quite high — nearly $\$ 200,000$ for the full sample and $\$ 400,000$ for the 0.2 bandwidth, with even larger upper bounds. ${ }^{17}$ Cost per job estimates declined in the 2000 s, reaching as low as $\$ 81,000$ after the Great recession, though confidence intervals are wide and suggest that the cost could have been as large as $\$ 188,000 /$ job.

While we have focused on cumulative 3-year jobs impact, Figure 6 shows that the cumulative effect at other horizons yield similar cost per job-year estimates. The figure plots estimated coefficients for the post-2000 period with 0.2 bandwidth and shows that cumulative estimates are quite persistent over the first 5 years. Estimates for longer horizons are not feasible with our data as the LP framework requires more data for longer horizons.

\section{Conclusion}

\footnotetext{
${ }^{17}$ Note that confidence intervals for cost per job may not exactly align with the bounds for the coefficients as they are nonlinear functions and their intervals have been estimated using delta method.
} 
Using state-level data from 1990 to 2013, we propose a new instrument to estimate the federal Medicaid assistance multiplier and present dynamic and long-term estimates of the multiplier. We find that the long-standing discontinuity in the slope of FMAP with respect to state RPCPI also induces a corresponding discontinuity in state federal Medicaid assistance. We posit that this discontinuity is otherwise uncorrelated with local economic conditions and show that nonMedicaid spending and most other covariates do not exhibit a similar discontinuity.

Our preferred IV estimates, employing a narrow bandwidth around the discontinuity, suggest that the multiplier from federal Medicaid dollars was very small in the 1990's expansion but rose to 1.5 during the Great Recession. On average from 1990-2010, federal Medicaid assistance through FMAP transfers have a modest positive multiplier - an additional $\$ 100,000$ in federal Medicaid assistance creates about 0.75 jobs over three years, yielding a statistically significant employment impact of 0.25 job-years at a cost per job of $\$ 400,000$, with an implied multiplier of 0.27 . Full sample estimates using all data yield a somewhat larger, though still modest, multiplier of 0.5 at a cost per job year of $\$ 200,000$.

This relatively modest macroeconomic stimulus from FMAP transfers should not be conflated with the overall welfare effects of the Medicaid program, which extends well beyond its multiplier effects through its impact on health and well-being of the target population. Furthermore, in line with this literature, we ignore contractionary effects (experienced by other states) from financing federal FMA.

While we break new ground in finding a new instrument to estimate the outside-financed geographic cross-section fiscal multiplier, our estimates do come with some important caveats. First, instrument weakness with narrower bandwidths precludes us from using Mean Squared Error (MSE)-optimal bandwidths, which turn out to be quite small. Secondly, our estimates should be viewed as a local average treatment effect (LATE) specific to states that would alter their Medicaid spending due to the FMAP slope discontinuity - and hence would get more or fewer federal Medicaid dollars than would be the case otherwise.

With these caveats, we anticipate our estimates being still useful in assessing the stimulative effect of nearly $\$ 400$ billion annually sent to states as federal Medicaid assistance through FMAP, accounting for more than half of all federal grants to states. Our results suggest that the regular FMAP transfers during normal times are not very stimulative. However, our estimates imply that $\$ 50$ billion provided to states as fiscal relief through a 6.2 percentage point 
increase in FMAP rate during the Covid-19 downturn was likely effective in spurring economic activity. 


\section{References}

Bellemare, M. F., Masaki, T., \& Pepinsky, T. B. (2017). Lagged explanatory variables and the estimation of causal effect. The Journal of Politics, 79(3), 949-963.

https://doi.org/10.1086/690946

Calonico, S., Cattaneo, M.D. and Titiunik, R., 2014a. Robust nonparametric confidence intervals for regression-discontinuity designs. Econometrica, 82(6), pp.2295-2326.

https://doi.org/10.3982/ecta11757

Calonico, S., Cattaneo, M.D. and Titiunik, R., 2014b. Robust data-driven inference in the regression-discontinuity design. Stata Journal, 14(4), pp.909-946.

https://doi.org/10.1177/1536867x1401400413

Chodorow-Reich, Gabriel. 2019. "Geographic Cross-Sectional Fiscal Spending Multipliers: What Have We Learned?," American Economic Journal: Economic Policy, v11(2):1-34.

https://doi.org/10.1257/pol.20160465

Chodorow-Reich, G., Feiveson, L., Liscow, Z., \& Woolston, W. G. (2012). Does state fiscal relief during recessions increase employment? Evidence from the American Recovery and Reinvestment Act. American Economic Journal: Economic Policy, 4(3), 118-45.

https://doi.org/10.1257/pol.4.3.118

Card, D., Lee, D.S., Pei, Z. and Weber, A., 2015. Inference on causal effects in a generalized regression kink design. Econometrica, 83(6), 2453-2483.

https://doi.org/10.3982/ecta11224

Congressional Budget Office. 2018. Options for Reducing the Deficit: 2019 to 2028," Congressional Budget Office: Washington, D.C.

Congressional Budget Office. 2012. Estimated Impact of the American Recovery and Reinvestment Act on Employment and Economic Output from October 2011 Through December 2011. A CBO Report. Congressional Budget Office: Washington, D.C.

Conley, T. G., \& Dupor, B. (2013). The American Recovery and Reinvestment Act: Solely a government jobs program? Journal of Monetary Economics, 60(5), 535-549.

https://doi.org/10.1016/i.jmoneco.2013.04.011

Council of Economic Advisers, Economic Report of the President, March 2014.

Council of Economic Advisers, "Missed Opportunities the Consequences of State Decisions not to Expand Medicaid," CEA report, July 2014.

Dupor, B., \& Rodrigo, G. (2017). The Aggregate and Relative Economic Effects of Medicaid and Medicare Expansions.

Gelman, A., \& Imbens, G. (2019). Why high-order polynomials should not be used in regression discontinuity designs. Journal of Business \& Economic Statistics, 37(3), 447-456. 
Fieldhouse, A. J., Mertens, K., \& Ravn, M. O. (2018). The macroeconomic effects of government asset purchases: Evidence from postwar us housing credit policy. The Quarterly Journal of Economics, 133(3), 1503-1560.

https://doi.org/10.1093/qje/qjy002

Jordà, Ò., (2005). "Estimation and Inference of Impulse Responses by Local Projections," American Economic Review, v95(1): 161-182.

https://doi.org/10.1257/0002828053828518

Kliff, T. (2012, July 10). Medicaid's stimulative effect [Blog post]. Retrieved from https:/www.washingtonpost.com/news/wonk/wp/2012/07/10/medicaids-stimulative-effect/

Landais, Camille. 2015. "Assessing the Welfare Effects of Unemployment Benefits Using the Regression Kink Design.” American Economic Journal: Economic Policy 7 (4): 243-278.

https://doi.org/10.1257/pol.20130248

Lundqvist, H., Dahlberg, M., \& Mörk, E. (2014). Stimulating local public employment: Do general grants work?. American Economic Journal: Economic Policy, 6(1), 167-92.

https://doi.org/10.1257/pol.6.1.167

Leung, P., 2016. Four Essays on the Economics of Social Programs (Doctoral dissertation). Retrieved from http://arks.princeton.edu/ark:/88435/dsp018s45qc191.

McCrary, J., 2008. Manipulation of the running variable in the regression discontinuity design: A density test. Journal of Econometrics, 142(2), pp.698-714.

https://doi.org/10.1016/j.jeconom.2007.05.005

Mitchell, A. (2020). Medicaid's Federal Medical Assistance Percentage (FMAP). Retrieved from https://sgp.fas.org/crs/misc/R43847.pdf

Nakamura, E., \& Steinsson, J. (2014). Fiscal Stimulus in a Monetary Union: Evidence from US Regions. American Economic Review, 104(3), 753-792.

https://doi.org/10.1257/aer.104.3.753

Zhuan Pei, David S. Lee, David Card \& Andrea Weber (2021): Local Polynomial Order in Regression Discontinuity Designs, Journal of Business \& Economic Statistics, https://doi.org/10.1080/07350015.2021.1920961

Ramey, V. A., \& Zubairy, S. (2018). Government Spending Multipliers in Good Times and in Bad: Evidence from US Historical Data. Journal of Political Economy, 126(2), 850-901. https://doi.org/10.1086/696277

Serrato, J. C. S., \& Wingender, P. (2016). Estimating local fiscal multipliers (No. w22425). National Bureau of Economic Research.

https://doi.org/10.3386/w22425 
Wilson, Daniel J., 2012. "Fiscal Spending Jobs Multipliers: Evidence from the 2009 American Recovery and Reinvestment Act," American Economic Journal: Economic Policy, 4(3): 251-282 https://doi.org/10.1257/pol.4.3.251 


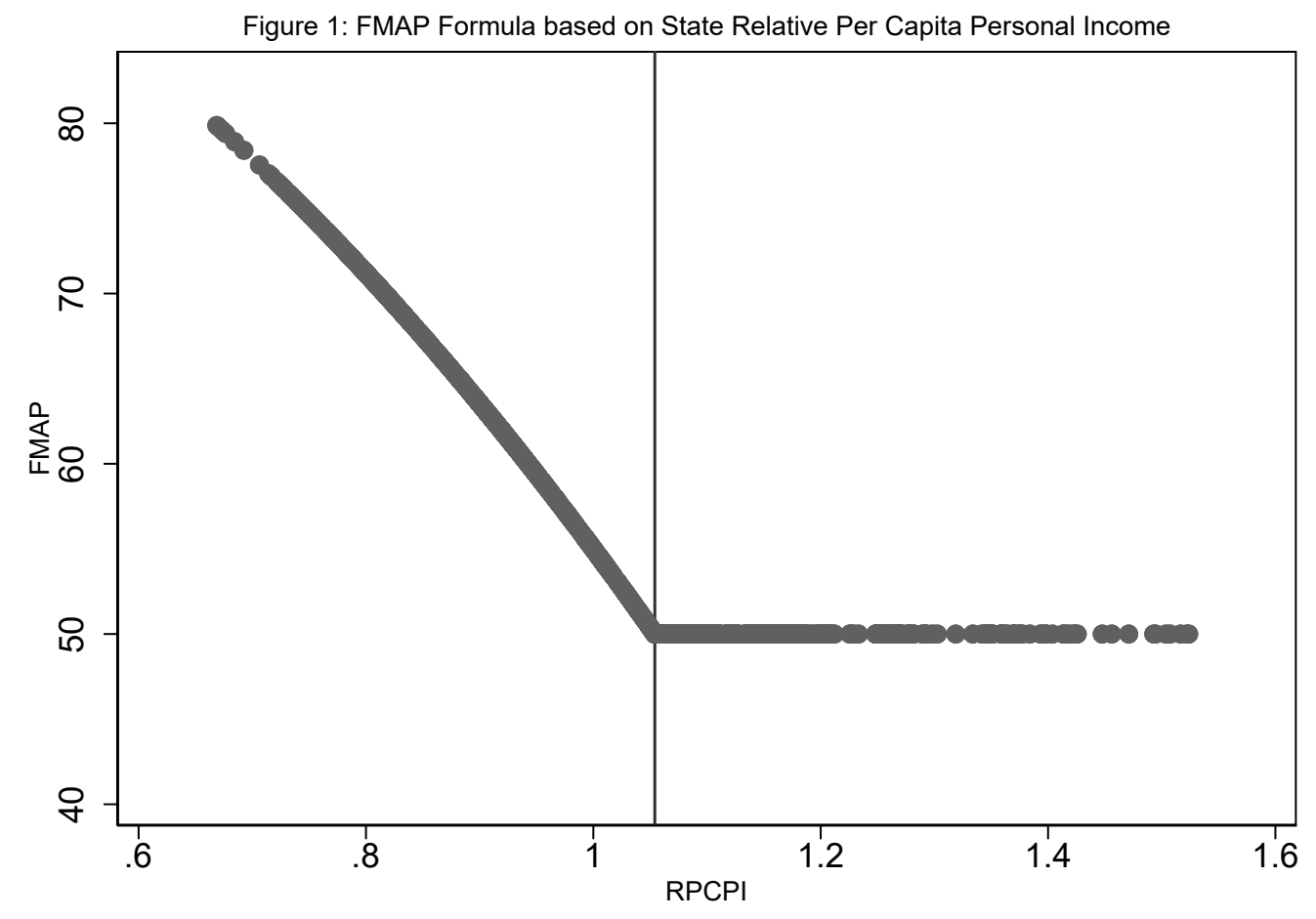

The figure plots the exact formula-based relationship between Federal Medical Assistance Percentage (FMAP) and the running variable - state's per capita personal income relative to the nation $(R P C P I)$. FMAP equals $1-0.45 * R P C I^{2}$ and is a declining function of $R P C P I$ for values less than 1.054. FMAP reaches a floor of 50 percent when $R P C P I$ exceeds 1.054, inducing a slope discontinuity in FMAP-RPCPI relationship. 


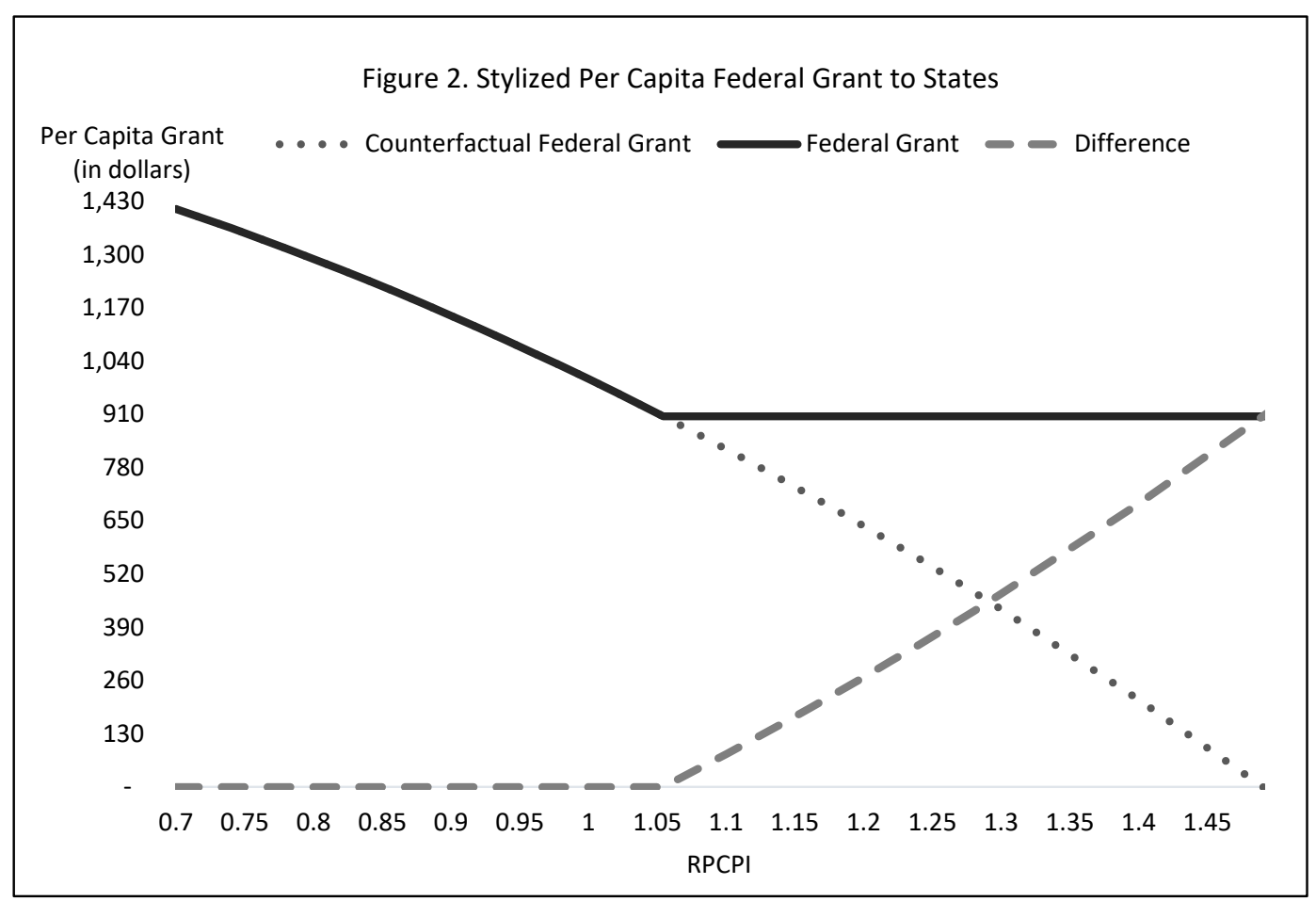

Notes: Calculations are based on a stylized state with Medicaid expenditures equal to the national average of $\$ 1,811$ (2018) per capita. The federal grant varies based on the actual range of the PCPI ratio for US states. For PCPI ratios exceeding 1.054, the grant hits a floor of $\$ 906$ per capita. The difference between this floor and the near-linear relationship can be viewed as an exogenous bonus to states beyond the kink. 
Figure 3: McCrary Test for Manipulation of Running variable

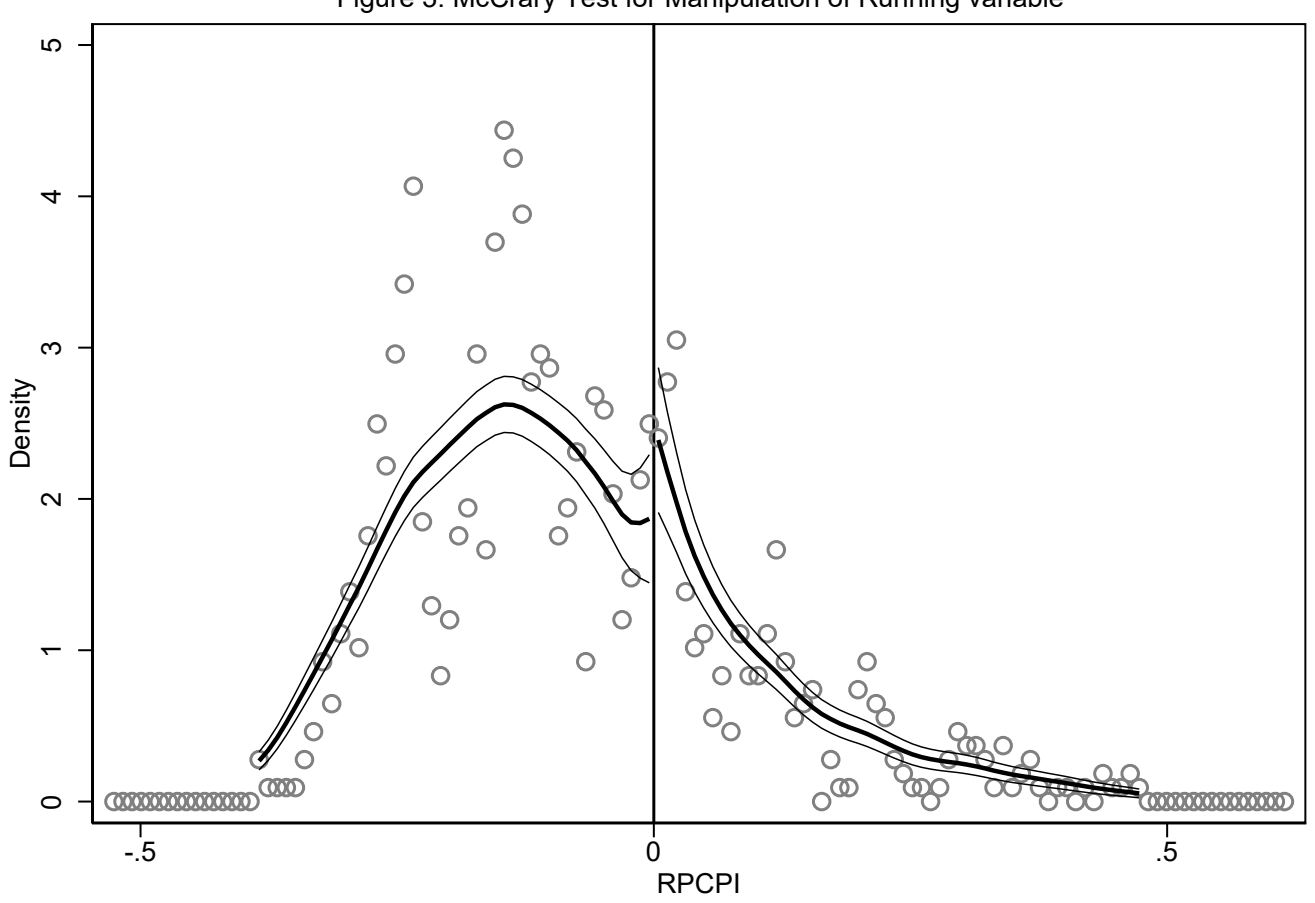

The figure plots the density of the normalized running variable (RPCPI-1.054) on the either side of the FMAP discontinuity. 

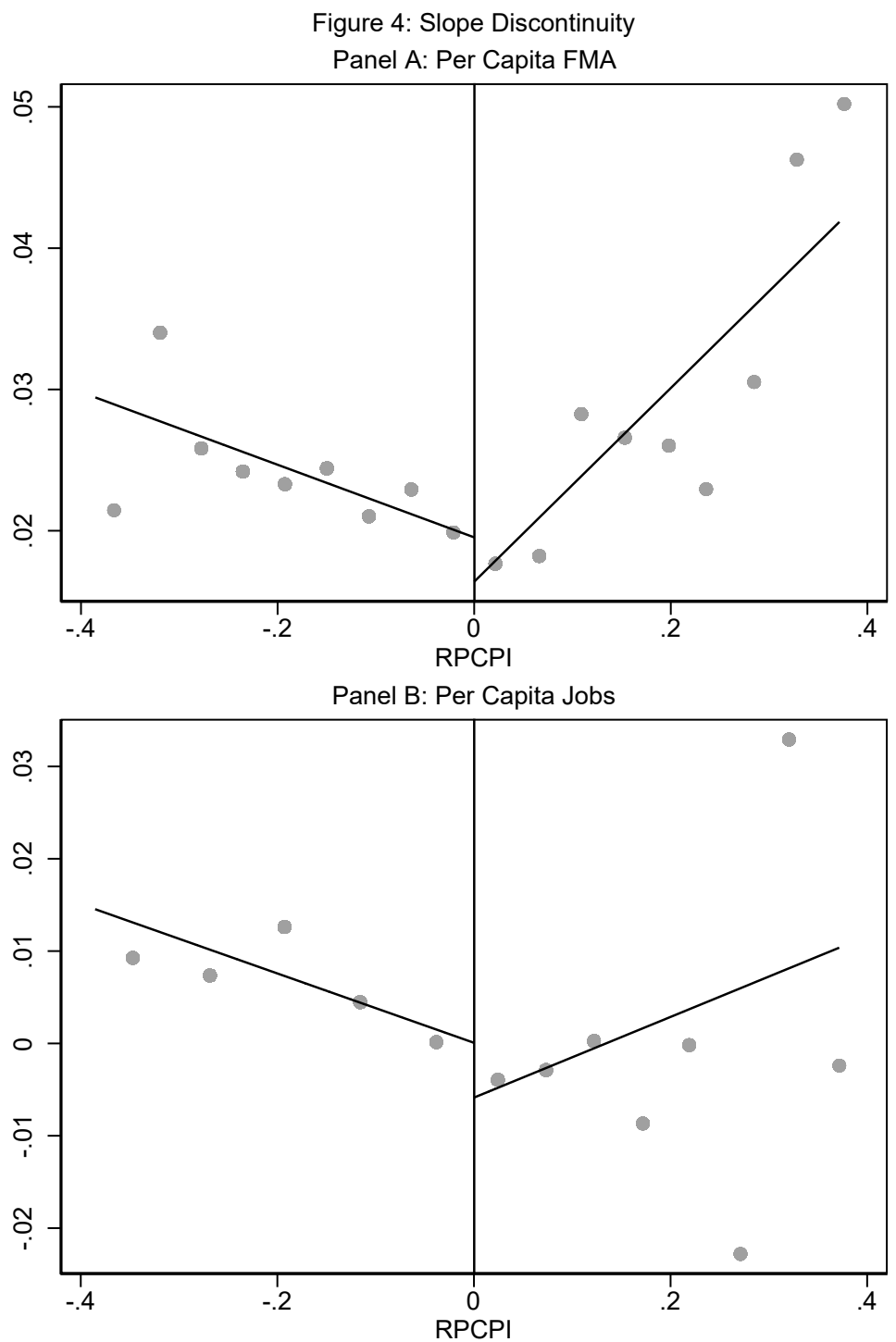

The figure plots binned sample means with the underlying linear fit on either side of RPCPI normalized to equal zero at FMAP kink. The number of bins is selected using IMSE-optimal evenly-spaced method proposed in Calonico, Cattaneo. and Titiunik (2014b) for the full sample (bandwidth 0.4). 
Figure 5: Implied Multipliers

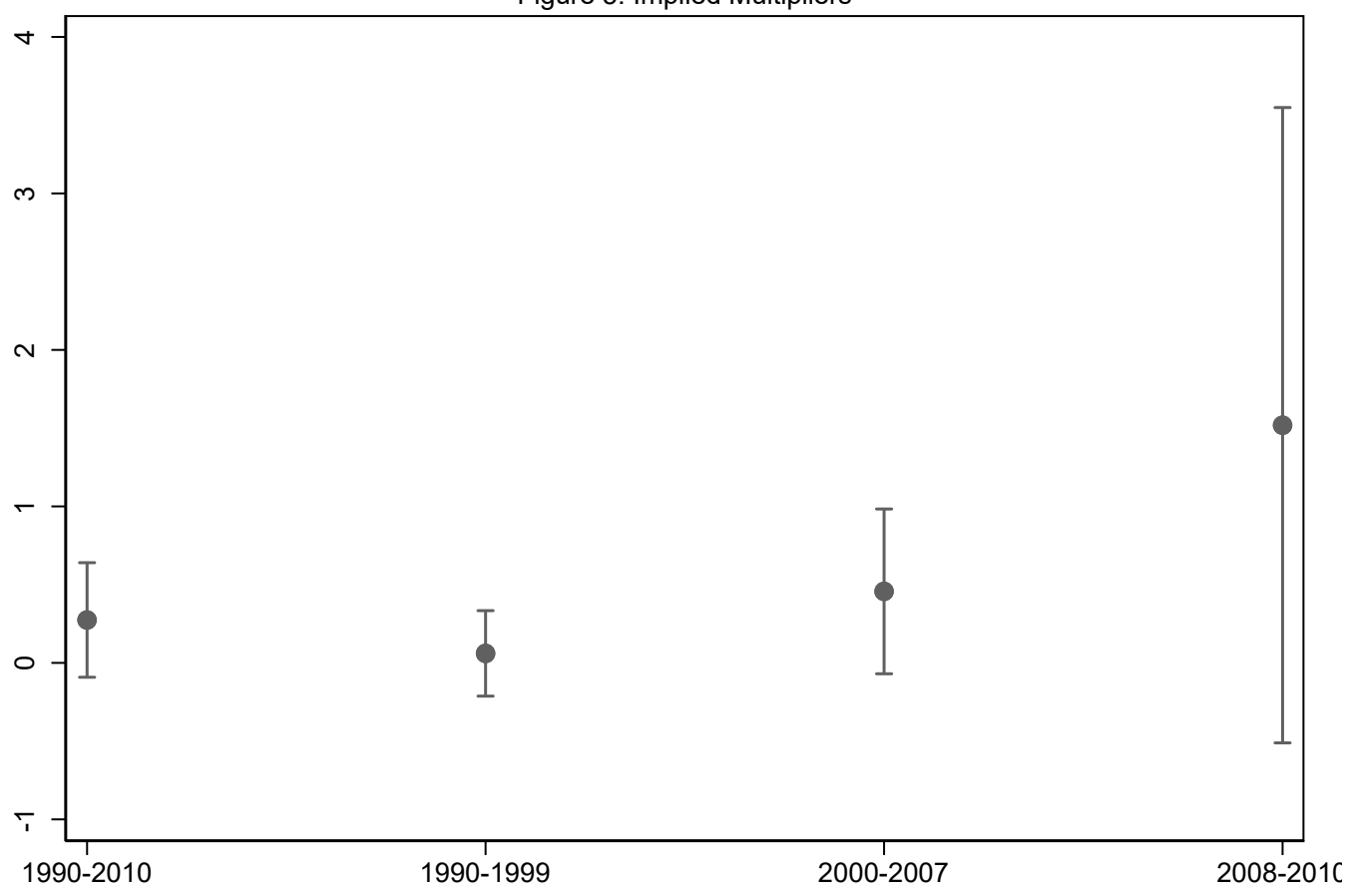

The figure plots implied multiplier and $95 \%$ confidence intervals for 0.2 bandwidth reported in Panel B of Table 8 . The implied multiplier is estimated as $\$ 108,700 /\left(\$ 100,000 /\left(\beta_{1} / 3\right)\right)$ using estimates of $\beta_{1}$ for 0.2 bandwidth from estimating equation (5). Estimates of $\beta_{1}$ are reported in Table 7. Confidence intervals are estimated using delta method. 
Figure 6: Cumulative Jobs Impact of FMA: 2000-2010

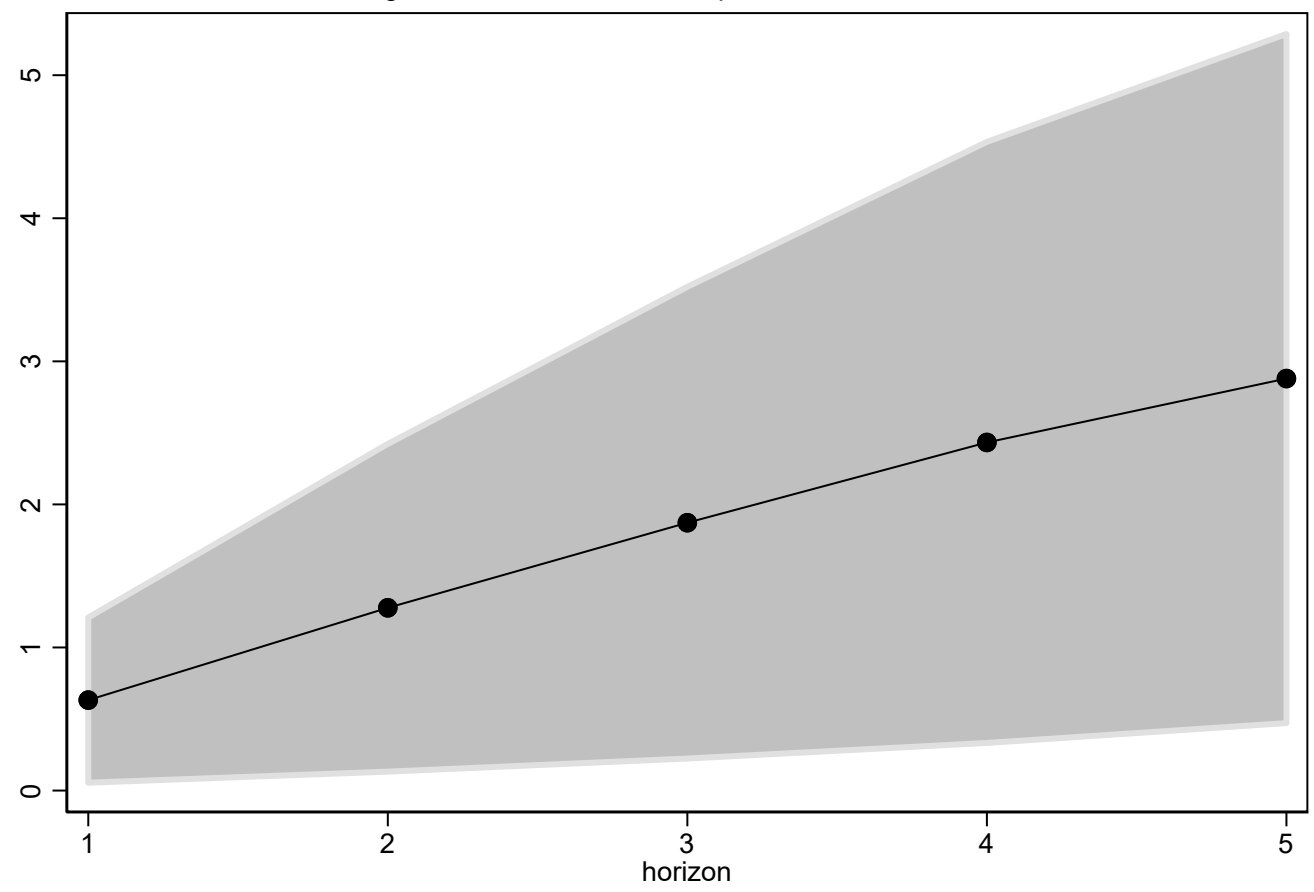

Notes: The figure plots the coefficients on cumulative FMA $\left(\beta_{1}^{H}\right)$ at horizons $(\mathrm{H})$ ranging from year 1 through year 5 (see equation (5)). cumulative $\mathrm{H}$-year future change in per capita jobs All regressions control for running variable (normalized RPCPI); year effects; first lag of share of union workers, share of manufacturing in state GDP, state population, and per capita real GDP; and demographic covariates--share of state population over age 65; female; white non-Hispanic; black; Hispanic; with a high school diploma; and those with any college education. 
Table 1: Summary Statistics

\begin{tabular}{|c|c|c|c|c|}
\hline & Mean & SD & Min & $\operatorname{Max}$ \\
\hline Outcome var. (cumul per capita jobs) ${ }^{\psi}$ & .002 & .04 & -0.173 & .133 \\
\hline Endogenous var. (cumul. per capita FMA) ${ }^{x}$ & .023 & .01 & 0.007 & 081 \\
\hline IV (norm. RPCPI X Above) & .029 & .072 & 0.000 & .394 \\
\hline Running var. (RPCPI - 1.054) & -.089 & .15 & -0.385 & .394 \\
\hline Lagged union coverage & 14.663 & 5.986 & 3.300 & 31.9 \\
\hline Lagged manuf'g share of GDP & 14.869 & 6.679 & 0.299 & 31.467 \\
\hline Lagged pop (millions) & 5.463 & 6.066 & 0.454 & 36.961 \\
\hline Lagged GDP per capita & 44884.69 & 16902.712 & 23904.338 & 176245.2 \\
\hline Age $65+$ & 15.835 & 2.171 & 6.000 & 21.666 \\
\hline Female & 51.832 & 1.001 & 49.319 & 54.966 \\
\hline White & 77.198 & 15.724 & 18.155 & 98.825 \\
\hline Black & 10.078 & 11.087 & 0.114 & 67.581 \\
\hline Hispanic & 6.698 & 8.337 & 0.091 & 42.834 \\
\hline High school & 29.725 & 9.338 & 2.041 & 43.747 \\
\hline Any college & .48 & .068 & 0.230 & .632 \\
\hline Jobs/pop & .464 & .096 & 0.339 & 1.208 \\
\hline Medicaid spending per capita & 928.071 & 408.212 & 223.286 & 2739.4 \\
\hline FMA/pop & 554.927 & 248.816 & 111.643 & 1865.547 \\
\hline Non-Medicaid exp/pop $(\$ 100,000)$ & .047 & .02 & -0.007 & .192 \\
\hline TANF exp/pop $(\$ 100,000)$ & .001 & .001 & 0.000 & .004 \\
\hline FMAP & 60.087 & 8.472 & 50.000 & 80.18 \\
\hline RPCPI & .965 & .15 & 0.669 & 1.448 \\
\hline
\end{tabular}

Notes: The table presents unweighted averages of variables across states. See equation (3) for definition of cumulative outcome and endogenous variables. ${ }^{\psi}$ Outcome variable is cumulative 3 -year future change in per capita jobs;

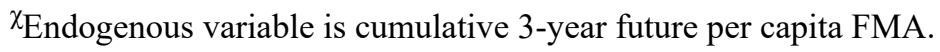


Table 2. P-Values for Test of Slope Discontinuity in Other Covariates

\begin{tabular}{lcccc}
\hline & 0.1 & 0.2 & 0.3 & 0.4 \\
\hline Non-Medicaid spending/pop & 0.2063 & 0.4722 & 0.9509 & 0.7211 \\
TANF spending/pop & 0.3565 & 0.2396 & 0.6029 & 0.4290 \\
Lagged union coverage & 0.7340 & 0.3189 & 0.2980 & 0.1028 \\
Lagged manuf'g share of GDP & 0.3785 & 0.5163 & 0.9717 & 0.9472 \\
Lagged pop (millions) & 0.4995 & 0.8039 & 0.1798 & 0.0504 \\
Lagged GDP per capita & 0.1070 & 0.9863 & 0.6238 & 0.3008 \\
Age 65+ & 0.1419 & 0.5660 & 0.3664 & 0.2272 \\
Female & 0.1907 & $0.0226^{*}$ & $0.0079^{* *}$ & $0.0030^{* *}$ \\
White & 0.9321 & 0.9549 & 0.5529 & 0.3733 \\
Black & 0.6797 & 0.1581 & 0.1099 & 0.0810 \\
Hispanic & $0.0294^{*}$ & 0.6343 & 0.9612 & 0.6661 \\
High School & 0.0747 & 0.5740 & 0.4863 & 0.5522 \\
Any college & 0.4317 & 0.1659 & 0.0693 & 0.0948 \\
\hline
\end{tabular}

Notes: The reports p-values on the test of significance of $R \widehat{P C P I} \times$ Above from a simple regression of the indicated covariate as the dependent variable on the running variable $\widehat{R P C P I}$ and the interaction term $\overrightarrow{R P C P I} \times$ Above. 
Table 3. Basic Full Sample Estimates

\begin{tabular}{lcccc}
\hline & $\begin{array}{c}(1) \\
\text { Non-Medicaid } \\
\text { Spending }\end{array}$ & $\begin{array}{c}(2) \\
\text { Medicaid } \\
\text { Spending }\end{array}$ & $\begin{array}{c}(3) \\
\text { FMA }\end{array}$ & Jobs \\
\hline RPCPI X Above & 0.038 & $0.012^{*}$ & $0.052^{* *}$ & $0.078^{* *}$ \\
& $(0.037)$ & $(0.007)$ & $(0.017)$ & $(0.030)$ \\
\hline Observations & 1000 & 1068 & 1068 & 1068 \\
R-Sq & 0.501 & 0.692 & 0.694 & 0.714 \\
\hline Notes: * p $<0.10, * *$ p $<0.05$. Standard errors clustered by state in parentheses. Estimates based on annual state-level \\
panel data from 1990-2010. Data sources include BLS, CPS, BEA, CMS, and HHS. All dependent variables are in \\
per-capita terms. Dependent variables for the first stage regression in column (3) and for the reduced form regression \\
in column (4) are both calculated as 3-year cumulative. All regressions control for the running variable (RPCPI); year \\
effects; first lag of share of union workers, share of manufacturing in state GDP, state population, and per capita real \\
GDP; and demographic covariates--share of state population over age 65; female; white non-Hispanic; black; \\
Hispanic; with a high school diploma; and those with any college education. See equation (2).
\end{tabular}


Table 4. Sensitivity of OLS and IV to Fixed Effects (Dependent Variable: Per Capita Jobs)

\begin{tabular}{|c|c|c|c|c|}
\hline & $\begin{array}{l}(1) \\
\text { OLS }\end{array}$ & $\begin{array}{c}(2) \\
\text { OLS with Fixed } \\
\text { Effects }\end{array}$ & $\begin{array}{l}\text { (3) } \\
\text { IV }\end{array}$ & $\begin{array}{c}(4) \\
\text { IV with Fixed } \\
\text { Effects }\end{array}$ \\
\hline Per Capita FMA & $\begin{array}{l}0.671 * * \\
(0.265)\end{array}$ & $\begin{array}{l}1.676^{* *} \\
(0.794)\end{array}$ & $\begin{array}{l}1.485 * * \\
(0.571)\end{array}$ & $\begin{array}{c}12.715 \\
(12.028)\end{array}$ \\
\hline $\begin{array}{l}\text { Observations } \\
\text { R-Sq } \\
\text { First Stage F } \\
\text { Underid P-val }\end{array}$ & $\begin{array}{c}1068 \\
0.719\end{array}$ & $\begin{array}{c}1068 \\
0.784\end{array}$ & $\begin{array}{l}1068 \\
0.704 \\
9.058 \\
0.004\end{array}$ & $\begin{array}{l}1068 \\
0.299 \\
0.629 \\
0.428\end{array}$ \\
\hline \multicolumn{5}{|c|}{$\begin{array}{l}\text { Notes: }{ }^{*} \mathrm{p}<0.10,{ }^{* *} \mathrm{p}<0.05 \text {. Standard errors clustered by state in parentheses. Estimates based on annual state-level } \\
\text { panel data from } 1990-2010 \text {. Data sources include BLS, CPS, BEA, CMS, and HHS. Dependent variable is cumulative } \\
\text { 3-year future change in per capita jobs; the endogenous variable is cumulative } 3 \text {-year future per capita FMA; for IV } \\
\text { models, instrument is the product of RPCPI and a dummy variable for RPCPI exceeding FMAP slope discontinuity } \\
\text { of } 1.054 \text { (RPCPI X 1(RPCPI }>1.054) \text { ). All regressions control for running variable (normalized RPCPI); year effects; } \\
\text { first lag of share of union workers, share of manufacturing in state GDP, state population, and per capita real GDP; } \\
\text { and demographic covariates--share of state population over age } 65 \text {; female; white non-Hispanic; black; Hispanic; with } \\
\text { a high school diploma; and those with any college education. See equation (2). }\end{array}$} \\
\hline
\end{tabular}


Table 5. IV Estimates of Jobs Impact of FMA: Robustness across Covariates (Dependent Variable: Per Capita Jobs)

\begin{tabular}{lccccccc}
\hline & $(1)$ & $(2)$ & $(3)$ & $(4)$ & $(5)$ & $(6)$ & $(7)$ \\
\hline Per Capita FMA & $0.873^{* *}$ & $0.660^{* *}$ & $0.620^{*}$ & $1.485^{* *}$ & $1.916^{* *}$ & $2.054^{* *}$ & $1.861^{* *}$ \\
& $(0.234)$ & $(0.230)$ & $(0.328)$ & $(0.571)$ & $(0.601)$ & $(0.670)$ & $(0.598)$ \\
& & & & & & & \\
Year Fixed Effects & No & Yes & Yes & Yes & Yes & Yes & Yes \\
& & & & & & & \\
Economic & No & No & Yes & Yes & Yes & Yes & Yes \\
& & & & & & & \\
Demographic & No & No & No & Yes & Yes & Yes & Yes \\
& & & & & & & \\
Region FE & No & No & No & No & Yes & Yes & Yes \\
& & & & & & & \\
Region X Year FE & No & No & No & No & No & Yes & Yes \\
& & & & & & & \\
Y Lags & No & No & No & No & No & No & Yes \\
\hline Observations & 1068 & 1068 & 1068 & 1068 & 1068 & 1068 & 1068 \\
Cost/Job Year (000) & 344 & 454 & 484 & 202 & 157 & 146 & 161 \\
Implied Multiplier & 0.316 & 0.239 & 0.225 & 0.538 & 0.694 & 0.744 & 0.674 \\
R-Sq & NA & 0.676 & 0.686 & 0.704 & 0.715 & 0.793 & 0.810 \\
First Stage F & 7.608 & 7.913 & 14.699 & 9.058 & 11.152 & 8.772 & 8.989 \\
Underid P-val & 0.030 & 0.025 & 0.001 & 0.004 & 0.007 & 0.011 & 0.012 \\
\hline
\end{tabular}

Notes: ${ }^{*} \mathrm{p}<0.10,{ }^{* *} \mathrm{p}<0.05$. Standard errors clustered by state in parentheses. Estimates based on annual state-level panel data from 1990-2010. Data sources include BLS, CPS, BEA, CMS, and HHS. Dependent variable is cumulative 3 -year future change in per capita jobs; the endogenous variable is cumulative 3-year future per capita FMA; for IV models, instrument is the product of RPCPI and a dummy variable for RPCPI exceeding FMAP slope discontinuity of 1.054 (RPCPI X 1(RPCPI>1.054)). All regressions control for running variable (normalized RPCPI); economic covariates include first lag of share of union workers, share of manufacturing in state GDP, state population, and per capita real GDP; and demographic covariates--share of state population over age 65; female; white non-Hispanic; black; Hispanic; with a high school diploma; and those with any college education. See equation (2). 
Table 6. IV Estimates of Jobs Impact of FMA: by Year (Dependent Variable: Per Capita Jobs)

(1)

\begin{tabular}{lcccc} 
& $(1)$ & $(2)$ & $(3)$ & $(4)$ \\
& $1990-2010$ & $1990-1999$ & $2000-2007$ & $2008-2010$ \\
\hline Per Capita FMA & $1.485^{* *}$ & 0.752 & $2.181^{* *}$ & 2.685 \\
& $(0.571)$ & $(0.632)$ & $(0.861)$ & $(2.023)$ \\
\hline Observations & 1068 & 510 & 408 & 150 \\
Cost/Job Year (000) & 202 & 399 & 138 & 112 \\
Implied Multiplier & 0.538 & 0.249 & 0.831 & 1.088 \\
R-Sq & 0.704 & 0.513 & 0.629 & 0.782 \\
First Stage F & 9.058 & 12.559 & 5.403 & 3.229 \\
Underid P-val & 0.004 & 0.001 & 0.024 & 0.115
\end{tabular}

Notes: $* \mathrm{p}<0.10, * * \mathrm{p}<0.05$. Standard errors clustered by state in parentheses. Estimates based on annual state-level panel data from 1990-2010. Data sources include BLS, CPS, BEA, CMS, and HHS. Dependent variable is cumulative 3 -year future change in per capita jobs; the endogenous variable is cumulative 3-year future per capita FMA; for IV models, instrument is the product of RPCPI and a dummy variable for RPCPI exceeding FMAP slope discontinuity of 1.054 (RPCPI X 1(RPCPI>1.054)). All regressions control for running variable (normalized RPCPI); year effects; first lag of share of union workers, share of manufacturing in state GDP, state population, and per capita real GDP; and demographic covariates--share of state population over age 65; female; white non-Hispanic; black; Hispanic; with a high school diploma; and those with any college education. See equation (2). 
Table 7: IV Estimates of Jobs Impact of FMA: Sensitivity to Bandwidth (Dependent Variable: Per Capita Jobs)

Panel A: 1990-2010

\begin{tabular}{lcccc}
\hline & $(1)$ & $(2)$ & $(3)$ & $(4)$ \\
& 0.1 & 0.2 & 0.3 & 0.4 \\
\hline Per Capita FMA & -1.077 & 0.749 & 0.776 & $1.485^{* *}$ \\
& $(2.843)$ & $(0.510)$ & $(0.666)$ & $(0.571)$ \\
\hline Observations & 355 & 736 & 1003 & 1068 \\
Cost/Job Year (000) & -279 & 400 & 386 & 202 \\
Implied Multiplier & -0.400 & 0.274 & 0.281 & 0.538 \\
R-Sq & 0.742 & 0.752 & 0.747 & 0.704 \\
First Stage F & 1.146 & 13.649 & 5.517 & 9.058 \\
Underid P-val & 0.249 & 0.004 & 0.014 & 0.004 \\
\hline
\end{tabular}

Panel B: 1990-1999

\begin{tabular}{lcccc}
\hline & $(1)$ & $(2)$ & $(3)$ & $(4)$ \\
& 0.1 & 0.2 & 0.3 & 0.4 \\
\hline Per Capita FMA & -2.603 & 0.182 & 0.078 & 0.752 \\
& $(3.710)$ & $(0.417)$ & $(0.547)$ & $(0.632)$ \\
\hline Observations & 159 & 348 & 482 & 510 \\
Cost/Job Year (000) & -115 & 1651 & 3870 & 399 \\
Implied Multiplier & -0.884 & 0.061 & 0.026 & 0.249 \\
R-Sq & 0.621 & 0.636 & 0.603 & 0.513 \\
First Stage F & 5.343 & 11.709 & 9.944 & 12.559 \\
Underid P-val & 0.029 & 0.003 & 0.002 & 0.001 \\
\hline
\end{tabular}

Panel C: 2000-2007

\begin{tabular}{lcccc}
\hline & $(1)$ & $(2)$ & $(3)$ & $(4)$ \\
& 0.1 & 0.2 & 0.3 & 0.4 \\
\hline Per Capita FMA & 2.990 & $1.186^{*}$ & 3.106 & $2.181^{* *}$ \\
& $(2.760)$ & $(0.697)$ & $(2.294)$ & $(0.861)$ \\
\hline Observations & 145 & 279 & 380 & 408 \\
Cost/Job Year (000) & 100 & 253 & 97 & 138 \\
Implied Multiplier & 1.160 & 0.457 & 1.182 & 0.831 \\
R-Sq & 0.679 & 0.700 & 0.524 & 0.629 \\
First Stage F & 4.010 & 16.833 & 1.946 & 5.403 \\
Underid P-val & 0.072 & 0.012 & 0.133 & 0.024 \\
\hline
\end{tabular}

Panel D: 2008-2010

\begin{tabular}{lcccc}
\hline & $(1)$ & $(2)$ & $(3)$ & $(4)$ \\
& 0.1 & 0.2 & 0.3 & 0.4 \\
\hline Per Capita FMA & -0.068 & 3.720 & 3.394 & 2.685 \\
& $(0.759)$ & $(2.537)$ & $(3.394)$ & $(2.023)$ \\
\hline Observations & 51 & 109 & 141 & 150 \\
Cost/Job Year (000) & -4414 & 81 & 88 & 112 \\
Implied Multiplier & -0.029 & 1.519 & 1.374 & 1.088
\end{tabular}



$\mathrm{R}-\mathrm{Sq}$
0.913
0.721
0.751
0.782
First Stage F
2.964
5.488
1.280
3.229
Underid P-val
0.080
0.055
0.245
0.115

Notes: $* \mathrm{p}<0.10, * * \mathrm{p}<0.05$. Standard errors clustered by state in parentheses. Estimates based on annual state-level panel data from 1990-2010. Data sources include BLS, CPS, BEA, CMS, and HHS. Dependent variable is cumulative 3-year future change in per capita jobs; the endogenous variable is cumulative 3-year future per capita FMA; for IV models, instrument is the product of RPCPI and a dummy variable for RPCPI exceeding FMAP slope discontinuity of 1.054 (RPCPI X 1(RPCPI>1.054)). All regressions control for running variable (normalized RPCPI); year effects; first lag of share of union workers, share of manufacturing in state GDP, state population, and per capita real GDP; and demographic covariates--share of state population over age 65; female; white non-Hispanic; black; Hispanic; with a high school diploma; and those with any college education. See equation (2). 
Table 8: Implied Multiplier from FMA

Panel A: Full sample

\begin{tabular}{|c|c|c|c|c|}
\hline & $\begin{array}{c}(1) \\
1990-2010 \\
\end{array}$ & $\begin{array}{c}(2) \\
1990-1999 \\
\end{array}$ & $\begin{array}{c}(3) \\
2000-2007\end{array}$ & $\begin{array}{c}(4) \\
2008-2010\end{array}$ \\
\hline Implied Multiplier & $\begin{array}{c}0.538 * * \\
{[0.132,0.944]}\end{array}$ & $\begin{array}{c}0.249 \\
{[-0.161,0.658]}\end{array}$ & $\begin{array}{c}0.831 * * \\
{[0.188,1.475]}\end{array}$ & $\begin{array}{c}1.088 \\
{[-0.518,2.694]}\end{array}$ \\
\hline Observations & 1068 & 510 & 408 & 150 \\
\hline \multicolumn{5}{|c|}{ Panel B: Bandwidth 0.2} \\
\hline & $\begin{array}{c}(1) \\
1990-2010\end{array}$ & $\begin{array}{c}(2) \\
1990-1999\end{array}$ & $\begin{array}{c}(3) \\
2000-2007\end{array}$ & $\begin{array}{c}(4) \\
2008-2010 \\
\end{array}$ \\
\hline Implied Multiplier & $\begin{array}{c}0.274 \\
{[-0.092,0.640]}\end{array}$ & $\begin{array}{c}0.061 \\
{[-0.212,0.334]}\end{array}$ & $\begin{array}{c}0.457 * \\
{[-0.069,0.983]}\end{array}$ & $\begin{array}{c}1.519 \\
{[-0.511,3.549]}\end{array}$ \\
\hline Observations & 736 & 348 & 279 & 109 \\
\hline
\end{tabular}

Notes: ${ }^{*} \mathrm{p}<0.10,{ }^{* *} \mathrm{p}<0.05$. Standard errors clustered by state in parentheses. Estimates based on annual state-level panel data from 1990-2010. Data sources include BLS, CPS, BEA, CMS, and HHS. Implied multiplier is estimated as $\$ 108,700 /\left(\$ 100,000 /\left(\beta_{1} / 3\right)\right)$ using estimates of $\beta_{1}$ for 0.2 bandwidth from estimating equation (5). Estimates of $\beta_{1}$ are reported in Table 7. Confidence intervals are estimated using delta method. 
Appendix Table 1: Implied Cost per Job

Panel A: Full sample

\begin{tabular}{lcccc}
\hline & $(1)$ & $(2)$ & $(3)$ & $(4)$ \\
& $1990-2010$ & $1990-1999$ & $2000-2007$ & $2008-2010$ \\
\hline Cost/Job Year (\$1000) & $202 * *$ & 399 & $138^{* *}$ & 112 \\
& {$[50,354]$} & {$[-258,1055]$} & {$[31,244]$} & {$[-53,277]$} \\
\hline Observations & 1068 & 510 & 408 & 150 \\
\hline \multicolumn{5}{c}{ Panel B: Bandwidth 0.2} \\
\\
\hline Cost/Job Year (\$1000) & $(1)$ & $(2)$ & & \\
& $1990-2010$ & $1990-1999$ & $2000-2007$ & $2008-2010$ \\
\hline Observations & 400 & 1651 & $253 *$ & 81 \\
\hline
\end{tabular}

Notes: $* \mathrm{p}<0.10, * * \mathrm{p}<0.05$. Standard errors clustered by state in parentheses. Estimates based on annual state-level panel data from 1990-2010. Data sources include BLS, CPS, BEA, CMS, and HHS. Cos per job is estimated as $\$ 100,000 /\left(\beta_{1} / 3\right)$ using estimates of $\beta_{1}$ for 0.2 bandwidth from estimating equation (5). Estimates of $\beta_{1}$ are reported in Table 7. Confidence intervals are estimated using delta method. 
Appendix Table 2: IV Estimates of Cumulative Jobs Impact of FMA by Time Horizon (Dependent Variable: Per Capita Jobs)

(Bandwidth 0.2)

Panel A: 1990-2010

\begin{tabular}{lccccc}
\hline & $(1)$ & $(2)$ & $(3)$ & $(4)$ & $(5)$ \\
& Year 1 & Year 2 & Year 3 & Year 4 & Year 5 \\
\hline Per Capita FMA & 0.181 & 0.451 & 0.749 & 1.038 & 1.231 \\
& $(0.173)$ & $(0.346)$ & $(0.510)$ & $(0.661)$ & $(0.758)$ \\
\hline Observations & 736 & 736 & 736 & 736 & 699 \\
R-Sq & 0.762 & 0.762 & 0.752 & 0.738 & 0.728 \\
First Stage F & 13.214 & 13.400 & 13.649 & 13.954 & 14.287 \\
Underid P-val & 0.005 & 0.005 & 0.004 & 0.004 & 0.004 \\
\hline \multicolumn{5}{c}{} \\
& \multicolumn{7}{c}{ Panel B: 2000-2010 } & & \\
\hline & $(1)$ & $(2)$ & $(3)$ & $(4)$ & $(5)$ \\
& Year 1 & Year 2 & Year 3 & Year 4 & Year 5 \\
\hline Per Capita FMA & $0.632^{*}$ & $1.277^{*}$ & $1.872^{*}$ & $2.433 *$ & $2.880^{* *}$ \\
& $(0.352)$ & $(0.698)$ & $(1.005)$ & $(1.281)$ & $(1.468)$ \\
\hline Observations & 388 & 388 & 388 & 388 & 351 \\
R-Sq & 0.759 & 0.732 & 0.702 & 0.666 & 0.597 \\
First Stage F & 13.550 & 14.114 & 14.493 & 14.822 & 16.705 \\
Underid P-val & 0.017 & 0.016 & 0.015 & 0.014 & 0.012 \\
\hline
\end{tabular}

Notes: $* \mathrm{p}<0.10, * * \mathrm{p}<0.05$. Standard errors clustered by state in parentheses. Estimates based on annual state-level panel data from 1990-2010. Data sources include BLS, CPS, BEA, CMS, and HHS. Dependent variable is cumulative future change in per capita jobs at different horizons; the endogenous variable is cumulative future per capita FMA at different horizons; instrument is the product of RPCPI and a dummy variable for RPCPI exceeding FMAP slope discontinuity of 1.054 (RPCPI X 1(RPCPI >1.054)). All regressions control for running variable (normalized RPCPI); year effects; first lag of share of union workers, share of manufacturing in state GDP, state population, and per capita real GDP; and demographic covariates--share of state population over age 65; female; white non-Hispanic; black; Hispanic; with a high school diploma; and those with any college education. See equation (2). 